\title{
CONTEXTOS ORTOGRÁFICOS DO SISTEMA ELIS - SINAIS COM MÃO DE APOIO
}

\author{
ORTOGRÁFICS CONTEXTS OF THE SYSTEM ELIS - BASE HAND SIGNS \\ CONTEXTOS ORTOGRÁFICOS DEL SISTEMA ELIS - SEÑAS \\ CON MANO DE APOYO
}

\author{
Vinicius Afonso de Camargo* \\ Mariângela Estelita Barros **
}

\section{Resumo}

O presente artigo, de cunho teórico-analítico, tem o objetivo de perceber e compreender como são estabelecidos certos contextos ortográficos do sistema brasileiro de escrita das línguas de sinais (ELiS), e especificamente fazer o levantamento de todos os sinais com mão de apoio que apresentam dois pontos de articulação (PA), a partir do corpus criado em projeto realizado em 2014 pelo Laboratório de Leitura e Escrita das Línguas de Sinais (LALELIS), da Faculdade de Letras, da Universidade Federal de Goiás. Para que a análise linguística deste sistema seja estabelecida, este estudo se debruçará teoricamente no livro ELiS: Sistema brasileiro de escrita das línguas de sinais, Barros (2015) e no Novo Dicionário Enciclopédico Ilustrado Trilíngue da Língua Brasileira de Sinais, de Capovilla, Raphael e Mauricio (2013).

Palavras-chave: ELiS. Escrita de Sinais. Sinais com mão de apoio. Ponto de Articulação da mão dominante.

\section{Introdução}

As diversas Línguas de Sinais (LS) são usadas pelas comunidades surdas ao redor do mundo e se distinguem das Línguas Orais (LO), principalmente, pela modalidade de realização, uma vez que as LO utilizam o canal oral-auditivo e as LS utilizam o canal visoespacial. As LS, que durante muitos anos não foram consideradas idiomas, adquiriram esse

\footnotetext{
*Graduado no Curso de Letras: Libras pela Faculdade de Letras da Universidade Federal de Goiás, UFG, Goiânia. Professor Intérprete no Colégio Estadual Damiana da Cunha, Goiânia.E-mail: vihmacio@gmail.com.

** Doutora em Letras e Linguística pela Universidade Federal de Goiás, UFG, Goiânia. Professora da Universidade Federal de Goiás, UFG, Goiânia. Criadora do Sistema Brasileiro de Escrita das Línguas de Sinais ELiS. E-mail: estelitabrasil@gmail.com
} 
status a partir do empenho de linguistas que dedicaram anos de estudos para demonstrar que, como qualquer outra língua, as LS apresentam todos os níveis linguísticos, como a fonética, a fonologia, a morfologia, a sintaxe e a semântica. Assim, o reconhecimento das LS desfaz o mito de que essas línguas são apenas um conjunto de gestos ou mímica.

Apesar de a Libras ter sido reconhecida legalmente como língua recentemente (Lei $n^{\circ} 10.436 / 2002$ ), ela já possui um sistema de escrita criado e desenvolvido respeitando sua estrutura linguística, a ELiS (BARROS, 2015). Este sistema foi escolhido por nós para uma análise profunda, com o propósito de enriquecer sua descrição e agregar-lhe valores, dando continuidade ao trabalho realizado pelo Laboratório de Leitura e Escrita das Línguas de Sinais (LALELIS), instalado na Faculdade de Letras, da Universidade Federal de Goiás, no qual todos os sinais do dicionário DEIT-Libras (CAPOVILLA, RAPHAEL e MAURICIO, 2013) foram escritos com o sistema ELiS. Estes sinais escritos em ELiS vieram a compor o corpus desta pesquisa.

No presente artigo, apresentaremos o resultado de nossa pesquisa, a qual teve o objetivo de analisar sinais com mão de apoio que apresentam dois pontos de articulação. Segundo as regras estabelecidas para a ELiS em Barros (2015), os sinais com mão de apoio apenas comportam um ponto de articulação, que é o ponto da mão não-dominante, no entanto, encontramos no referido corpus, alguns sinais com mão de apoio que apresentam ponto de articulação para ambas as mãos. Nosso objetivo foi analisar o porquê desse desvio da regra, sua real necessidade e se fosse o caso, sugerir um adendo à regra principal já descrita.

\section{Referencial teórico}

Este trabalho trata de escrita e ortografia relacionadas a línguas de sinais, focando especificamente no sistema ELiS. Para discutirmos a escrita em geral, fundamentamos nosso trabalho principalmente em Fayol (2014), que aborda a aquisição da escrita do ponto de vista cognitivo, e para a questão da ortografia, baseamo-nos em Morais (2000, 2001), que trata da aquisição e da importância da ortografia. Barros (2015) foi o referencial utilizado para explorar as regras da ELiS, pois é onde estas encontram-se descritas em mais detalhes. Além destes autores, realizamos uma revisão de três modelos fonológicos das línguas de 
sinais a fim de compreendermos melhor a relação entre os elementos formadores destas línguas, os quais são representados na escrita.

\subsection{A escrita e a ortografia}

Para começarmos a abordar a questão da escrita, é preciso entender que há três modalidades de língua, a modalidade falada, a modalidade sinalizada e a modalidade escrita. As modalidades falada e sinalizada são utilizadas principalmente em momentos de interação síncrona, com interlocutores presentes (fisicamente ou virtualmente), sendo que a modalidade falada é própria das línguas orais e a sinalizada, das línguas de sinais. Ambas podem ser representadas pela modalidade escrita, a qual normalmente estabelece uma relação assíncrona entre autor e leitor.

Teorizando sobre a escrita em geral, esta pode ser considerada uma manifestação formal do letramento. É adquirida geralmente no âmbito formal da escola, em que a criança, por volta dos seis ou sete anos, começa a aprender a se comunicar através da modalidade padrão escrita (NOBRE, 2011, p. 4). A modalidade escrita é um sistema abstrato, capaz de representar a fala ou a sinalização por meio de símbolos gráficos. Assim, a escrita permite um registro permanente dos mais diferentes gêneros textuais, atendendo aos mais diversos objetivos dos autores, desde um simples bilhete mnemônico a elaborados textos literários e científicos, valendo-se de suportes digitais ou físicos.

Como toda escrita é feita por meio de signos gráficos, ela está sujeita a regras gramaticais e ortográficas, para que seja possível a compreensão entre quem escreve e quem lê. A palavra "ortografia" é composta por dois radicais de origem grega: "orto", com o significado de "direito", "exato" e "grafia", que é "escrita". Sendo assim, ortografia significa "escrita correta das palavras" (HOUAISS, 2001, p. 322). A ortografia estuda padrões para a escrita de uma língua e estabelece uma forma correta para cada palavra a partir de convenções, ou seja, algo que se define socialmente. A ortografia permite que maneiras diferentes de falar/sinalizar entre usuários de uma mesma língua sejam unificadas na escrita, possibilitando melhor entendimento entre as partes.

Isso nos mostra que a ideia de poder escrever como se fala, sem a necessidade de regras ortográficas pode ocasionar momentos de dificuldade na compreensão do texto, pois nas modalidades falada ou sinalizada, as pessoas podem variar a pronúncia, de acordo com 
regiões, idade, sexo, grupos socioculturais, a época em que estão inseridos e outros (MORAIS, 2001).

Morais (2000, p. 20) argumenta que, no que se refere à modalidade escrita, "quando consegue ler e escrever os primeiros textos, o indivíduo já apreendeu o funcionamento do sistema da escrita, mas desconhece a ortografia, o que faz que seus textos possuam muitos erros na escrita". As modalidades escritas são sistemas conceituais que representam as modalidades orais e sinalizadas relacionadas e precisam ser aprendidas e estudadas. Segundo Morais (2000, p. 20), “o conhecimento ortográfico é algo que a criança não pode descobrir sozinha, sem ajuda", pois é uma convenção. O mesmo acontece com adultos que estão aprendendo a escrita. Fayol (2014) também afirma que aprender a ler e escrever, ao contrário da oralidade/sinalização, demanda muita dedicação, pois envolve esforço consciente de atenção, memória e raciocínio. Logo, aprender a escrever é um processo contínuo, lento e árduo, construído ao longo de nossas vidas.

\subsection{Fonologia da Língua de Sinais}

A Fonologia pode ser compreendida como o estudo das menores unidades do léxico, cuja alteração causa mudança de significado. Valli et al. (2005, p. 17, apud COSTA, 2012) consideram que o termo "fonologia" se refere ao estudo de como os sinais são estruturados e organizados. Assim como explica Brentari:

\footnotetext{
A fonologia é o nível de análise gramatical em que as unidades estruturais primitivas sem significado são recursivamente combinadas para criar um número infinito de expressões significativas. É o nível de gramática que tem uma ligação direta com os sistemas fonéticos articulatórios e perceptuais, tanto os sistemas periféricos do par visual/gestual quanto do par auditivo/vocal (BRENTARI, 1998, p. 1-2, tradução nossa) $)^{1}$
}

Nas LS, essas menores unidades são os elementos dos chamados parâmetros, são eles: Configuração da Mão, que é a forma da mão durante a execução do sinal; Orientação, que a direção para onde está voltada a palma ou o dorso da mão; Ponto de Articulação, ou Localização, que é o local no espaço, ou ponto no corpo onde o sinal é realizado; Movimento, que é a ação que muda a configuração de mão, a orientação, ou a localização durante a realização do sinal; e Expressão Não-Manual, que são movimentos executados pela cabeça, pelos olhos, pelo tronco e outras partes do corpo que não as mãos ou os braços. 
Um dos primeiros estudos linguísticos das LS foi realizado por Stokoe, em 1960, por meio da análise da Língua de Sinais Americana (ASL). O teórico observou que essa língua era composta por três parâmetros: Configuração de Mão (CM), Ponto de Articulação (PA) e Movimento (M), os quais foram denominados pelo autor, respectivamente, de Dez, Tab e Sig. Os elementos desses parâmetros foram chamados por Stokoe, inicialmente, pelo termo "quirema" 2 (em inglês, "chereme"), porém, em pesquisas posteriores, tais parâmetros passaram a ser considerados elementos fonológicos e foram substituídos pelo termo "fonema", por apresentarem conceitos equivalentes aos das LO.

Dentre vários estudos linguísticos voltados para as LS, outro destaque é o estudo de Battison (1978), que identificou e acrescentou o quarto parâmetro ao sistema fonológico das LS: a Orientação. Consideraremos, ainda, como quinto parâmetro, a Expressão Não-Manual (ENM), sobre a qual não há consenso entre os diversos autores quanto ao seu status de parâmetro.

Os elementos destes parâmetros organizam-se de forma estruturada em cada língua, a fim de compor os sinais. Como explica Costa (2012), as LS têm regras e estrutura linguística complexa, com elementos organizacionais finitos e restrições nas combinações entre eles. A partir dos parâmetros estabelecidos, apresentaremos brevemente três modelos fonológicos das LS, que são o de Liddell e Jonhson, Modelo MH (Movement-Hold); o de Sandler, o Modelo HT (Hand Tier) e o de Brentari (1998), o MP (Modelo Prosódico).

O modelo Movement-Hold (MH), de Liddell e Jonhson, representa os aspectos simultâneos e sequenciais das LS, ampliando os tópicos dos M, possibilitando explicar vários dados fonológicos nas LS. A estrutura deste modelo está constituída em segmentos de preensão $^{3}$, em que as CM, PA, OP e os ENM são representados como feixes de traços articulatórios, e de segmentos de movimento ${ }^{4}$. Segundo este modelo, os sinais seriam sequências de segmentos de preensão e segmentos de movimento.

Sandler, por sua vez, apresenta o Modelo HT (Hand Tier), criado e desenvolvido a partir dos parâmetros de Stokoe (1960) e dos aspectos do modelo MH, desenvolvido por Liddell e Jonhson. Esse modelo foi o primeiro a representar o posicionamento da CM, e esta separadamente a nível fonológico, e propôs unidades de tempo que se associam às do modelo de Liddell e Jonhson. Enquanto no modelo MH as unidades de tempo são representadas por 
segmentos de Preensão e Movimento, as de Sandler são representadas por locações e movimentos.

Além dos modelos fonológicos apresentados anteriormente, temos o Modelo Prosódico (MP), criado por Brentari em 1998 e que surgiu a partir de duas bases teóricas: fonologia autossegmental e geometria de dados. Sua estrutura arbórea apresenta dois traços distintivos, organizados de forma hierárquica e sistematizada. São eles: traços inerentes ${ }^{5}$, que são realizados simultaneamente, e traços prosódicos ${ }^{6}$, executados sequencialmente. Brentari (1998) faz uma comparação entre a sonoridade das LO e das LS, destacando que, para o MP, o parâmetro de $\mathrm{M}$ se destaca dos demais em relação à percepção visual, e portanto, é o mais "sonoro" nas LS.

\subsection{A escrita da língua de sinas (ELiS)}

A ELiS (Escrita das Línguas de Sinais) foi criada pela linguista Mariângela Estelita Barros, professora da Faculdade de Letras da Universidade Federal de Goiás. Esse sistema de escrita possibilita o registro das línguas de sinais sem a mediação das línguas orais. O desenvolvimento desse sistema se divide em três fases (Barros, 2015): a criação em 1998, o aperfeiçoamento em 2008 e, nos dias atuais, sua divulgação e implementação. De acordo com a autora, esta última fase, além de necessária, é de extrema importância para a permanência da escrita na comunidade surda.

Barros (2015) explica que a ELiS é organizada de forma alfabética (um símbolo para cada elemento) e linear, com caracteres próprios, dispostos de acordo com a ordem natural de realização dos elementos durante os sinais. Barros (2015) denomina os símbolos/letras da ELiS de visografemas, por serem formas gráficas que representam elementos visuais. Ao todo são 95 visografemas, divididos em 4 grupos, Configuração de Dedos, Orientação da Palma, Ponto de Articulação e Movimento, que passamos a explicar a seguir:

Configuração de dedos - CD: a ideia de CD é diferente da de Configuração de Mão, por considerar, separadamente, o polegar e os demais dedos, em diferentes posições, ou seja, os visografemas de $\mathrm{CD}$ representam os dedos isoladamente. Estas $\mathrm{CD}$, quando combinadas, podem representar qualquer formato de mão, a partir de um total de apenas 10 visografemas. Devemos atentar que o caractere “.”, que indica a posição "fechado", é usado tanto para o polegar quanto para os demais dedos. Os visografemas de CD são: 
Subgrupo Polegar:

\begin{tabular}{|l|l|l|}
\hline fechado & \multicolumn{1}{|c|}{ na palma } & $<$ curvo \\
\hline$\backslash 3 \mathrm{D}$ & - horizontal & $\mathbf{1}$ vertical \\
\hline
\end{tabular}

Subgrupo demais dedos:

\begin{tabular}{|l|l|l|l|l|}
\hline fechado & $\mathbf{7}$ muito curvo & $\mathbf{7}$ curvo & $\mathbf{I}$ inclinado & $\mathbf{I}$ estendido \\
\hline
\end{tabular}

Orientação da palma - OP: esse grupo diz respeito à direção para onde a palma está voltada. Ele é composto por 6 visografemas e é o único grupo que não possui subgrupos. Seus visografemas são:

\begin{tabular}{|c|c|c|}
\hline$\square$ palma para frente & 回 palma para trás & ( palma para medial \\
\hline 崽 palma para distal & 日 palma para cima & 曰 palma para baixo \\
\hline
\end{tabular}

Ponto de articulação - PA: o grupo de PA representa os diversos pontos no corpo e no espaço de sinalização usados fonologicamente na Libras e em outras línguas de sinais. Ele é dividido em 4 subgrupos, sendo eles cabeça, tronco, membros e mão. Esse grupo possui um total de 35 visografemas.

Subgrupo cabeça:

\begin{tabular}{|c|c|c|}
\hline 口espaço à frente do rosto & 므 alto da cabeça & I-I lateral da cabeça \\
\hline II orelha & $=$ testa & $=$ sobrancelha \\
\hline$\ddot{-}$ olho & a maçã do rosto & $\perp \quad$ nariz \\
\hline$\doteq$ buço & $=$ boca & I dentes \\
\hline ๑o bochechas & $\sqcup$ queixo & 늘 abaixo do queixo \\
\hline
\end{tabular}

Subgrupo tronco:

\begin{tabular}{|c|c|c|}
\hline Tा pescoço & 百 espaço neutro & 亘 tórax \\
\hline Г lateral do corpo & 可 abdômen & \\
\hline
\end{tabular}

Subgrupo Membros:

\begin{tabular}{|l|l|l|l|}
\hline $\mathbf{L}$ braço inteiro & $\mathbf{L}$ ombro & $\mathbf{L}$ axila & $\mathbf{L}$ braço \\
\hline
\end{tabular}




\begin{tabular}{|l|l|l|l|l|}
\hline $\mathbf{L}$ cotovelo & $\mathbf{L}$ antebraço & $\mathbf{L}$ punho & $\overline{\mathbf{T}}$ perna \\
\hline
\end{tabular}

Subgrupo Mãos:

\begin{tabular}{|c|c|c|c|}
\hline palma da mão & $\boldsymbol{\nabla}$ dorso da mão & III dedos da mão & ㅁ) lateral da mão \\
\hline $\begin{array}{l}\text { Dintervalo entre } \\
\text { dedos }\end{array}$ & $\begin{array}{l}\text { एF articulação de } \\
\text { dedo }\end{array}$ & (口 ponta de dedos & \\
\hline
\end{tabular}

Movimento - M: neste grupo, está a junção de dois parâmetros o de M e ENM. Ele está dividido em 3 subgrupos, sendo eles movimento de braços, movimento de dedos e punho, e movimento sem as mãos.

Subgrupo Movimento de Braços:

\begin{tabular}{|c|c|c|c|}
\hline$\perp$ para frente & $\mathbf{T}$ para trás & $\begin{array}{l}¥ \text { para frente } \mathrm{e} \\
\text { para trás }\end{array}$ & $\uparrow$ para cima \\
\hline$\downarrow \quad$ para baixo & $\begin{array}{l}\text { 1 para cima e } \\
\text { para baixo }\end{array}$ & $\rightarrow$ para direita & $\leftarrow$ para esquerda \\
\hline $\begin{array}{l}\leftrightarrow \text { para esquerda } \\
\text { e direita }\end{array}$ & + para o meio & + para fora & $\begin{array}{l}\nearrow \text { para cima } \mathrm{e} \\
\text { direita }\end{array}$ \\
\hline $\begin{array}{l}\text { para cima e } \\
\text { esquerda }\end{array}$ & $\begin{array}{l}\text { y para baixo e } \\
\text { direita }\end{array}$ & $\begin{array}{l}\boldsymbol{\swarrow} \text { para baixo e } \\
\text { esquerda }\end{array}$ & n arco \\
\hline $\begin{array}{l}\mathbf{D} \\
\text { flexão/extensão do } \\
\text { braço }\end{array}$ & o circular vertical & $\begin{array}{l}0 \\
\text { horizontal }\end{array}$ & ○ circular frontal \\
\hline
\end{tabular}

Subgrupo Movimento de Dedos e Punho:

\begin{tabular}{|c|c|c|c|}
\hline$\underline{\Perp} \quad$ abrir a mão & $\overline{\mathbf{T}}$ fechar a mão & $\begin{array}{l}\text { \# abrir e fechar } \\
\text { a mão }\end{array}$ & $\begin{array}{ll}\text { 개 flexionar } & \text { os } \\
\text { dedos na } & 1^{\mathrm{a}} \\
\text { articulação }\end{array}$ \\
\hline 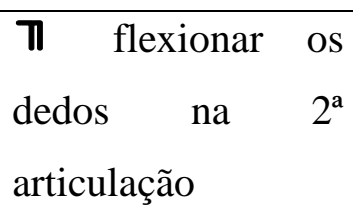 & $\begin{array}{l}\mathbf{V} \text { unir e separar } \\
\text { os dedos }\end{array}$ & $\begin{array}{l}\Omega \text { tamborilar os } \\
\text { dedos }\end{array}$ & $\begin{array}{l}\Omega \text { friccionar os } \\
\text { dedos }\end{array}$ \\
\hline L dobrar o punho & Lr mover o punho & Lo girar o punho & Lo girar o antebraço \\
\hline
\end{tabular}


lateralmente

Subgrupo Movimento Sem as Mãos:

\begin{tabular}{|c|c|c|c|}
\hline $\begin{array}{l}\text { @ negação com a } \\
\text { cabeça }\end{array}$ & $\begin{array}{l}\text { - afirmação com } \\
\text { a cabeça }\end{array}$ & $\begin{array}{l}\multimap \quad \text { língua na } \\
\text { bochecha }\end{array}$ & $\begin{array}{l}\text { 于 língua para } \\
\text { fora }\end{array}$ \\
\hline corrente de ar & $\begin{array}{l}\text { ㅍ vibração dos } \\
\text { lábios }\end{array}$ & $\begin{array}{l}\boldsymbol{\prime} \text { movimento } \\
\text { lateral do queixo }\end{array}$ & $\begin{array}{l}x \quad \text { murchar } \\
\text { bochechas }\end{array}$ \\
\hline o inflar bochechas & boca aberta & + piscar olho & girar tronco \\
\hline
\end{tabular}

Os 95 visografemas devem ser escritos em uma ordem fixa, obedecendo à sequência de grupos CD/OP/PA/M, como no sinal “-†回二๑”, que em português significa “doce”, em que _t são visografemas de $\mathrm{CD}$, 回 é uma $\mathrm{OP}$, 二 é um PA, e ๑ é um M. Porém, nem todos os sinais apresentam movimento fonológico, como podemos observar no sinal “_N旧号”, que no português tem o significado de "absurdo", em que _IN são visografemas de CD, 曰 é a OP, 드 é o PA, e não há visografema de M.

Além dos visografemas, a ELiS também possui diacríticos. Segundo Dubois (2001, p. 181), diacrítico "é um signo gráfico adjunto a um grafema simples do alfabeto, a fim de transcrever um fonema diferente daquele que transcreve esse grafema”. Na ELiS, a maioria dos diacríticos é usada à direita e acima do visografema que deverá modificar, e são caracteres em tamanho menor do que os visografemas. Podemos ver no exemplo do sinal “_t回三 $\perp ”$, que significa "obrigado", que o PA = "testa”, está acompanhado do diacrítico

`. Este diacrítico, que indica lateralidade, especifica que a porção da testa onde o sinal deverá

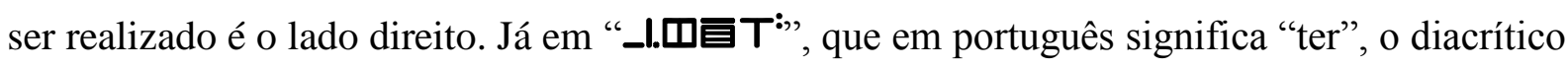
:, que é um diacrítico de repetição, se encontra adjunto ao M T , "para trás", e especifica que o M "para trás" deve ser realizado repetidamente.

Os diacríticos que ocupam outras posições são: diacríticos de contato, que são colocados abaixo do visografema de PA; diacrítico de união de dedos, que é inserido sobre o visografema de $\mathrm{CD}$, do subgrupo de demais dedos; diacrítico de união com o polegar, que é posto acima do visografema de $\mathrm{CD}$, também do subgrupo de demais dedos.

Atualmente, a ELiS tem sido tema de pesquisas, em monografias, dissertações, teses e produções independentes. Dentre pesquisas concluídas, estão as obras: ELiS - sistema 
brasileiro das línguas de sinais de Mariângela Estelita Barros, na qual essa escrita para as línguas de sinais é apresentada, e ELiS: internacionalização da escrita das línguas de sinais de Leandro Andrade Fernandes, na qual não só é comprovada a viabilidade do sistema ELiS em vinte línguas de sinais distintas, como também são apontadas mudanças necessárias para o aperfeiçoamento e utilização da escrita.

A ELiS é um sistema de escrita que permite que as línguas de sinais sejam registradas na modalidade escrita, e não apenas em vídeo, como já vinha sendo feito desde a disponibilização dessa tecnologia. Apesar de tanto a escrita como o vídeo serem formas de registro válidas para línguas de sinais, elas ocupam espaços diferentes na sociedade e servem a diferentes funções linguísticas. A difusão da escrita de sinais é importante, pois permite uma outra forma de expressão aos falantes de línguas de sinais, ampliando assim o alcance de seu universo linguístico, o que leva Barros (2015, p. 13) a afirmar que "a disseminação da possibilidade e da prática da escrita da Libras colabora com o empoderamento da comunidade surda".

\section{Análise}

Em seu livro, Barros (2015) afirma que quando se tem mais de uma possível forma de escrita para o mesmo sinal, deve-se escolher a que apresenta menos visografemas e menos diacríticos, ou seja, a mais simples. A escolha por uma forma em detrimento de outra, leva o sistema ao patamar de escrita ortográfica, ou seja, mais de uma forma escrita é passível de representar uma forma sinalizada, porém, apenas uma é aceita como correta.

Podemos notar que os sinais considerados na ELiS como "sinais com mão de apoio" são a simplificação de um determinado tipo de sinais realizado com duas mãos, em que uma das mãos exerce maior atividade sobre o sinal, sendo considerada a mão dominante (MD), e a outra mão é mais passiva, sendo denominada mão não-dominante (MND). De acordo com Brentari (1998):

Mão dominante: "A mão/braço usada para articular as formas soletradas e os sinais de uma mão é chamada de mão dominante (abreviada $\mathrm{M}_{1}$ ao longo deste livro); em sinais de duas mãos, a outra mão é a mão não-dominante (abreviado $\mathbf{M}_{2}$ )" (BRENTARI, 1998, p.7, tradução nossa) ${ }^{7}$. 
O sinal de abelha, por exemplo, é realizado com duas mãos e poderia ser escrito da

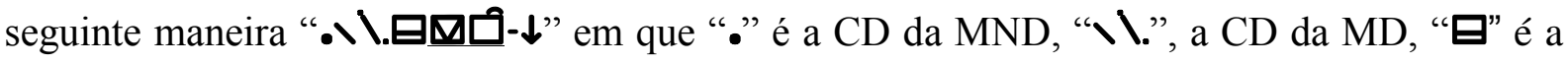
OP de ambas as mãos, “四” é o PA da MND que é tocado pelo PA “ם” da MD, “_" é a

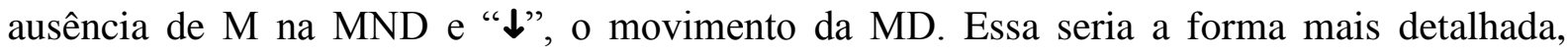
porém mais complexa, de se escrever o sinal. De acordo com as regras gerais da ELiS, a

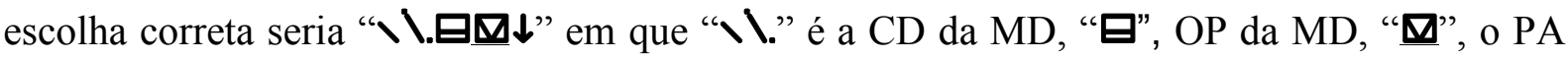
da MND e o “ $\downarrow$ ”, o movimento da MD.

Essa forma, ao mesmo tempo em que simplifica a escrita da palavra ao retirar os visografemas de $\mathrm{CD}$, OP e $\mathrm{M}$ da $\mathrm{MND}$, continua representando todos os elementos necessários para sua leitura/realização do sinal. Isso se dá pelo fato de que, ao executarmos a leitura da palavra "II.日四 $\downarrow$ ”, percebermos que a mão deve tocar o PA “四”, “dorso”. Por ser anatomicamente impossível que uma mão toque o seu próprio dorso, resta-nos apenas a opção de tocar o dorso da outra mão, da MND. Neste momento, as duas mãos passam a estar envolvidas na realização do sinal, porém, a MND participa apenas como PA, o que caracteriza o sinal como "sinal como mão de apoio". Barros (2015) explica as condições de restrição fonológica para que sinais sejam considerados do tipo "sinais com mão de apoio" dentro da ELiS:

Sinal com mão de apoio: é aquele no qual a mão não dominante atua apenas como ponto de articulação. Esse tipo de sinal, em sua forma escrita, assemelha-se a um sinal monomanual, porém, em sua realização, tem a aparência de um sinal bimanual, pois as duas mãos estão envolvidas. Algumas particularidades os distinguem dos bimanuais e dos monomanuais e algumas condições devem ocorrer simultaneamente para que um sinal seja considerado "com mão de apoio", são elas:

- A CD da mão de apoio deve ser $\_$, ou _t, ou it, ou•, ou em relaxamento, configuração próxima a $<7$;

- A orientação do eixo da palma da mão de apoio deve ser "para frente" $\left({ }^{\square}\right)$ ou "para a medial" $\left({ }^{\boxplus}\right)$;

- A OP de mão de apoio deve ser "para cima" $(\boxminus)$ ou "para baixo" $(\boxminus)$;

- O PA da mão de apoio deve ser a "palma" $(\square)$, “dorso" ( $\square$ ) "antebraço" (ட) ou "punho" (L):

- O M da mão de apoio deve ser inexistente (-) ou o mesmo M da mão dominante (BARROS, 2015, pag.83).

De acordo com as regras, os sinais de mão de apoio deveriam ser compostos pela estrutura CD, OP, PA e M, em que o PA seria apenas o da MND. Analisando o Novo Dicionário Enciclopédico Ilustrado Trilíngue da Língua Brasileira de Sinais, (Capovilla, Raphael e Maurício, 2013) escrito em ELiS, encontramos sinais de mão de apoio que 
possuem dois PAs, ou seja, PA da MND e PA da MD, tornando-se uma exceção às regras estabelecidas.

Normalmente, a parte da MD que toca ou se aproxima da MND são os dedos selecionados. Segundo Brentari, "dedos selecionados" são "os dedos de um formato de mão que podem se mover durante a produção de um sinal, ou que podem tocar o corpo - os 'dedos ativos"” (BRENTARI, 1998, p.7, tradução nossa) ${ }^{8}$. Porém, há sinais com mão de apoio em que outras partes da MD, ou do braço, tocam ou se aproximam da MND.É esse contexto fonológico atípico que define a necessidade da escrita do PA da MND e do PA da MD em um sinal do tipo de mão de apoio e configura uma situação de exceção à regra estabelecida para a escrita de sinais com mão de apoio.

Percebemos que é uma exceção, pois dentre as 10.296 entradas do referido dicionário escritas com a ELiS, 897 são sinais com mão de apoio e apenas 69 deles apresentam PA da MND e PA da MD. Esse número é ainda menor, caindo para 31 sinais, quando consideramos apenas as ocorrências type, ou seja, quando desprezamos as ocorrências repetidas. Uma das ocorrências que podemos citar a guisa de explicação, é o caso da primeira entrada para “deitar-se”, registrada no dicionário DEIT-Libras (Capovilla, Raphael e Maurício, 2013). Apresentamos a seguinte descrição fonológica para este sinal:

Tabela 1 - Descrição fonológica do sinal com mão de apoio "deitar-se"

\begin{tabular}{|c|c|c|}
\hline \multicolumn{3}{|c|}{ 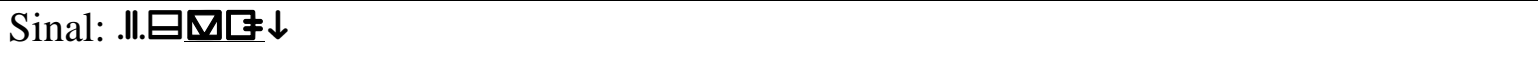 } \\
\hline \multicolumn{3}{|c|}{ Glosa: deitar-se } \\
\hline $\mathrm{CD}(\mathrm{MD})$ & $\begin{array}{l}\text { polegar fechado, dedos indicador e médio estendidos, dedos anular e } \\
\text { mínimo fechados }\end{array}$ & .ll. \\
\hline OP (MD) & para baixo & 日 \\
\hline PA (MND) & Dorso & $\nabla$ \\
\hline PA (MD) & articulação de dedos & ⿷ \\
\hline $\mathrm{M}(\mathrm{MD})$ & para baixo & $\downarrow$ \\
\hline
\end{tabular}

Se usássemos apenas as regras já descritas para sinais com mão de apoio, esse sinal

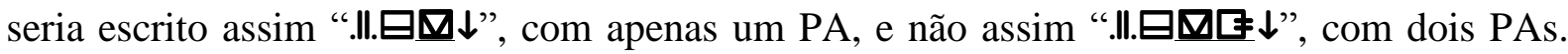
No entanto, de acordo com o conceito de "dedos selecionados" apresentado anteriormente, o 
qual explica a participação destes dedos durante a realização de um sinal, o PA da MD, que tocaria a mão de apoio, seriam estes dedos selecionados, .l., o que levaria a uma leitura/realização do sinal diferente da pretendida. Para que isso não ocorra, precisamos acrescentar o PA da MD, "articulação de dedo", que determinará que este é o ponto que deverá entrar em contato com o PA da MND. Assim, a escrita ortograficamente correta deste

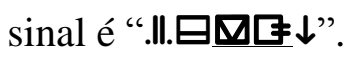

Assim, ao se acrescentar o PA de MD em um sinal qualquer com mão de apoio, compreende-se que, em vez de se usar os dedos selecionados da MD como PA, deve-se articular o sinal com os PAs da MND e da MD indicados na escrita. Sugerimos, então, que este contexto ortográfico seja considerado nas regras para sinais com mão de apoio e que a seguinte regra seja acrescida às demais descritas em Barros (2015), a fim de contemplá-lo: o Ponto de Articulação (PA) da mão dominante (MD) deve ser escrito em sinais com mão de apoio, quando o PA desta mão for outro que não os dedos selecionados.

Os sinais que apresentamos na tabela a seguir são os que foram encontrados no corpus dessa pesquisa. Eles se comportam da mesma maneira que o sinal "deitar-se" explicado anteriormente, ou seja, são sinais com mão de apoio que apresentam dois PAs em sua escrita devido ao fato de que o PA da MD é outro que não os dedos selecionados.

Tabela 2 - sinais com mão de apoio com dois PAs

\begin{tabular}{|c|c|}
\hline 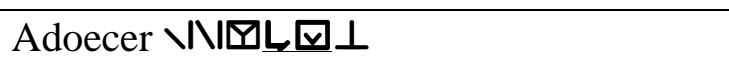 & 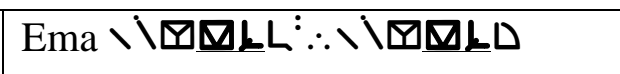 \\
\hline 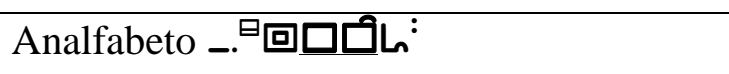 & Endereço _t甲 $t^{\boxminus}$ 回 \\
\hline 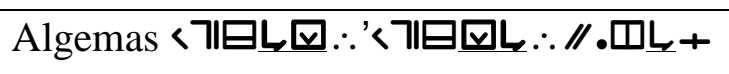 & 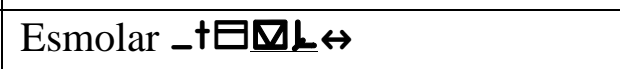 \\
\hline Alto(a) (estatura) I.⿴囗十 & Espátula .\#. ${ }^{\ominus}$ 回口冋L \\
\hline 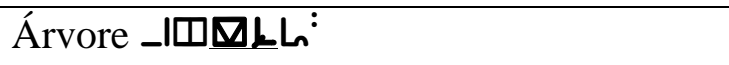 & 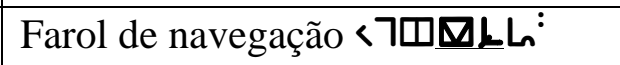 \\
\hline 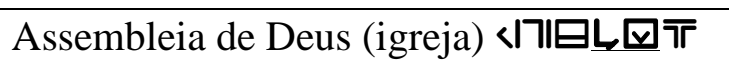 & Ferir _ł日டிவ \\
\hline 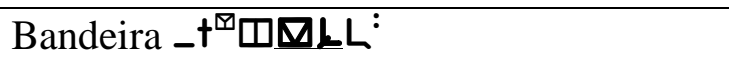 & Hotel _t甲⿴囗十口 \\
\hline 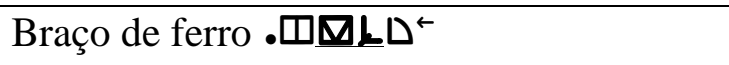 & 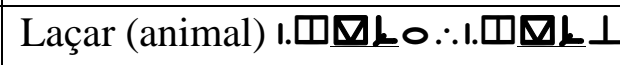 \\
\hline
\end{tabular}




\begin{tabular}{|c|c|}
\hline 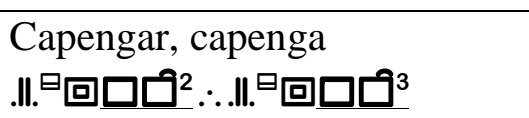 & Tédio (monotonia, mesmice) /十回四 \\
\hline 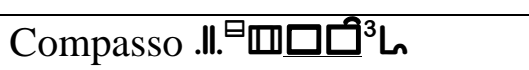 & Poema (1), poesia (1) ハハ. \\
\hline Coral I...I⿴囗十Lo & 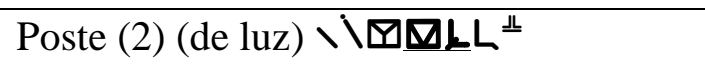 \\
\hline 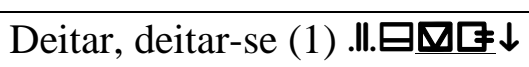 & 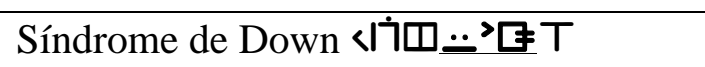 \\
\hline 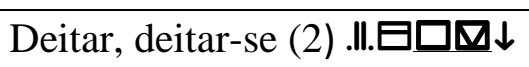 & 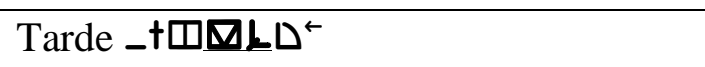 \\
\hline Dinossauro (1) $\backslash \nabla \nabla \mathbf{L}_{\leftrightarrow} \rightarrow$ & Motel _t' \\
\hline 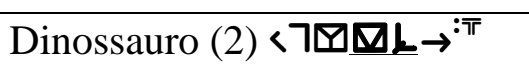 & 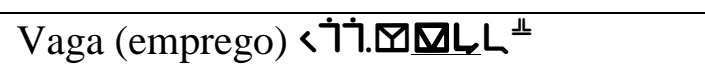 \\
\hline Impotência sexual I.⿴囗十k & \\
\hline
\end{tabular}

\section{Considerações finais}

A análise realizada expõe o quanto é importante e necessário acrescentar às regras já estabelecidas em Barros (2015) para sinais com mão de apoio, a descrição de um novo contexto ortográfico deste tipo de sinal, identificado a partir de nossos dados, e a regra que propomos para contemplá-lo.

Esta análise identificou o contexto em que dois PAs são utilizados em sinais com mão de apoio, e depreendeu, das ocorrências encontradas, a nova regra a ser acrescentada:

O Ponto de Articulação (PA) da mão dominante (MD) deve ser escrito em sinais com mão de apoio, quando o PA desta mão for outro que não os dedos selecionados.

A partir do exemplo do sinal para "deitar-se", apresentamos como ele seria escrito de acordo com as regras estabelecidas em Barros (2015) e como ele foi realmente escrito pela equipe do LALELIS, demonstrando discrepância entre eles e evidenciando a necessidade de atualização das regras para sinais com mão de apoio.

Este trabalho foi realizado com o objetivo de trazer contribuições à descrição da ELiS, no que tange aos sinais com mão de apoio, porém não esgota o assunto. Futuras pesquisas poderão verificar, por exemplo, quais são os PA de MD mais frequentes em sinais com mão 
de apoio e se eles variam de acordo com o corpus. Além deste contexto específico que foi alvo de nossa pesquisa, diversos outros aspectos da ELiS podem ser investigados e analisados do ponto de vista linguístico, a fim de que a descrição desse sistema possa ser cada vez mais precisa.

\begin{abstract}
The aim of this paper is to understand how certain orthographic contexts of the Brazilian sign language writing system (ELiS) are established. We specifically identified all the base hand signs with two points of articulation (PA) found in a corpus created by the project carried out in 2014 by the Laboratory of Sign Language Reading and Writing (LALELIS), Faculty of Letters, Federal University of Goiás. For the linguistic analysis of this system to be established, this study will theoretically focus on the book ELiS: Brazilian sign language writing system, Barros (2015) and New Illustrated Encyclopedic Dictionary Trilingual of the Brazilian Sign Language, by Capovilla, Raphael and Mauricio (2013).
\end{abstract}

Keywords: ELiS. Sign langugae writing. Base-hand signs. Point of articulation of the dominant hand.

\title{
Resúmen
}

Este artículo, de cuño teórico-analítico, tiene el objetivo de investigar los contextos ortográficos del sistema de escritura de las lenguas de signos (ELiS), haciendo una clasificación de todas las señas con mano de apoyo que presentan dos puntos de articulación (PA), a partir del corpus del proyecto realizado en 2014 por el Laboratorio de Lectura y Escritura de las Lenguas de Señas (LALELIS), de la Facultad de Letras, de la Universidad Federal de Goiás. Para que el análisis linguístico de este sistema sea establecido, este estudio tendrá como base teórica las obras: ELiS: Sistema brasileño de escrita de señas, de Barros (2015) y el Nuevo Diccionario Enciclopédico Ilustrado Trilingüe de la Lengua Brasileña de Señas de Capovilla, Raphael y Mauricio (2013).

Palabras clave: ELiS. Escritura de las Lenguas de Señas. Señas con mano de apoyo. Punto de Articulación de la mano dominante.

\section{Referências}

BARROS, M. E. ELiS: sistema brasileiro de escrita das línguas de sinais. Porto Alegre: Penso, 2015.

BATTISON, R. Lexical borrowing in American Sign Language. Silver Spring, MD: Linstok, 1978. 
BRENTARI, D. A prosodic model of sign language phonology. Cambridge MA: MIT Press, 1998.

CAPOVILlA, F. C.; RAPHAEL, W. D.; MAURICIO, A. C. L. Dicionário Enciclopédico Ilustrado Trilíngue: Língua de Sinais Brasileira. 3. ed. São Paulo: Edusp, 2013. 2 v.

COSTA, R. C. R. da. Proposta de instrumento para a avaliação fonológica da Língua Brasileira de Sinais: FONOLIBRAS. 2012. 232 f. Dissertação (Mestrado) - Curso de Letras, Instituto de Letras, Universidade Federal da Bahia, Salvador, 2012.

DUBOIS, J. (et alli). Dicionário de linguística. 8.ed. São Paulo: Cultrix, 2001.

FAYOL, M. Aquisição da escrita. Trad. Marcos Bagno. São Paulo: Parábola, 2014.

FERNANDES, L. A. ELiS: internacionalização da escrita das línguas de sinais. Saarbrücken: Novas Edições Acadêmicas, 2015.

HOUAISS, A.; SALLES, M. de. Minidicionário Houaiss da língua portuguesa. Rio de Janeiro: Objetiva, 2001.

LIDDEL, S. K.; JOHNSON, R. E. American sign language: the phonological base. Sign language studies, v. 64, 1989. p. 195-277.

MORAIS, A. G. de (Org.). O aprendizado da ortografia. 2. ed. Belo Horizonte: Autêntica, 2000. 144 p.

MORAIS, A. G. de. Ortografia: Ensinar e Aprender. 4. ed. São Paulo: Ática, 2001. 4 v.

NOBRE, L. L. Influência da linguagem oral na escrita. 2011. 20 f. TCC (Graduação) Curso de Especialização em Gramática e Ensino da Língua Portuguesa, Instituto de Letras, Universidade Federal do Rio Grande do Sul, Porto Alegre, 2011.

STOKOE, W. C. Sign Language structure. Silver Spring, MD: Linstok, 1960.

VALLI, C.; LUCAS, C.; MULROONEY, K. J. (org.). Linguistics of American Sign

Language: an introduction. 4. ed. Washington: Gallaudet University Press, 2005.

\section{Notas}

\footnotetext{
1 "Phonology is the level of grammatical analysis where primitive structural units without meaning are recursively combined to create an infinite number of meaningful utterances. It is the level of grammar that has a direct link with the articulatory and perceptual phonetic systems, either a visual/gestural pair or an auditory/vocal pair of peripheral systems".
} 
${ }^{2}$ Quirema: palavra originada do Grego e que tem o significado de menor unidade da mão, e corresponde ao fonema das línguas faladas.

${ }^{3}$ Segmentos de Preensão: momento em que as mãos estão em repouso durante o sinal.

${ }^{4}$ Segmento de Movimento: momento em que as mãos estão em ação durante o sinal.

${ }^{5}$ Traços Inerentes (TI): são propriedades específicas dos sinais que não se modificam.

${ }^{6}$ Traços Prosódicos (TP): são propriedades dos sinais que podem se modificar ou são realizados de forma dinâmica.

${ }^{7}$ Texto de Partida: Dominant hand: "The hand/arm used to articulate fingerspelled forms and one-handed signs is called the dominant hand (abbreviated $H_{l}$ throughout this book); in two-handed signs, the other hand is the nondominant hand (abbreviated $\mathrm{H}_{2}$ )".

${ }^{8}$ Selected fingers: "the fingers of a handshape that can move during the production of a sign, or that can touch the body - the 'active fingers"'. 